\title{
Acute myonecrosis in horse caused by Clostridium novyi type A
}

\author{
Luana D'avila Farias ${ }^{1}$, Marcos Da Silva Azevedo², Maria Elisa Trost ${ }^{3}$, \\ Flávio Desessards De La Côrte ${ }^{2}$, Luiz Francisco Irigoyen ${ }^{3}$, Agueda Castagna de Vargas ${ }^{1}$ \\ ${ }^{1}$ Departamento de Medicina Veterinária Preventiva, Universidade Federal de Santa Maria, \\ Santa Maria, RS, Brazil. \\ ${ }^{2}$ Departamento de Clínica de Grandes Animais, Universidade Federal de Santa Maria, Santa Maria, \\ RS, Brazil. \\ ${ }^{3}$ Laboratório de Patologia Veterinária, Universidade Federal de Santa Maria, Santa Maria, RS, Brazil.
}

Submitted: October 24, 2012; Approved: April 04, 2013.

\begin{abstract}
The objective of this study was to describe the first report involving a case of equine acute myonecrosis caused by C. novyi type A with an emphasis on clinical signs, the pathological and bacteriological analysis, and molecular identification of the microorganisms as the key of the definitive diagnosis.
\end{abstract}

Key words: malignant edema, Clostridium novyi, equine, anaerobe infection, 16SrRNA gene.

Clostridial myositis, also called malignant edema, is a disease that causes severe necrotizing soft tissue infections. In domestic animals, these infections are most common in cattle and sheep, with C. septicum, C. chauvoei, C. novyi and $C$. perfringens being the most frequently isolated causative pathogens (Songer, 2010).

Equine species are less commonly affected by malignant edema; however, there are published veterinary reports that describe muscle infections caused by the following Clostridium species: C. fallax, C. septicum, C. chauvoei, C. sporogenes and, more commonly, $C$. perfringens (Hagemoser et al., 1980; Coloe et al., 1983; Choi et al., 2003; Peek et al., 2003; Raymundo et al., 2010). Clostridium novyi infection in horses is less frequently and usually fatal (Valberg et al., 1984; Aleman et al., 2003).

This work describes the first report involving a case of acute myonecrosis in a horse caused by C. novyi type A that most likely began after an intramuscular injection. This report emphasizes the clinical signs, pathological findings and bacteriological and phylogenetic analyses of the microorganism as the key to the definitive diagnosis.

A three-year-old horse was admitted to a veterinarian hospital due to increased volume and lameness in the left pelvic limb shown in Figure 1A. The increased in volume started in the gluteal muscle, where the horse had been given an intramuscular injection of vitamin complex.

During the hospitalization period, the treatment instituted included vertical incisions into the injured muscle to drain foul exudate and gas; these incisions were washed with hydrogen peroxide and iodine solution as shown in Figure 1B. The systemic therapy included intravenous potassium penicillin (30.000 UI/kg QID), flunixin meglumine $(0.75 \mathrm{mg} / \mathrm{kg}$ TID), pentoxifylline (10 mg/kg BID), $100 \mathrm{~mL}$ of dimethylsulfoxide (DMSO) in $1 \mathrm{~L}$ of sodium chloride and 36 liters of lactated Ringers solution.

Blood samples were sent for complete blood counting and biochemistry analysis, and fluid and tissue samples were collected and sent for bacteriological examinations. The first hemogram showed no significant changes in relation to the erythrocytes; however, the level of fibrinogen was above the laboratory reference values (200$400 \mathrm{mg} / \mathrm{dL}$ ). The leukocyte count showed leukopenia with a left shift. The second test revealed a further increase in the fibrinogen level $(1000 \mathrm{mg} / \mathrm{dL})$ in addition to leukocytosis with neutrophilia and a regenerative shift to the left.

Microbiological growth was verified only in semisolid reinforced clostridial medium (Becton Dickinson \& Co, Circle Sparks, Maryland, USA), which exhibited turbidity and gas formation. The Gram stain of a smear from

Send correspondence to L.D. Farias. Departamento de Medicina Veterinária Preventiva, Universidade Federal de Santa Maria, Av. Roraima n. 1000, prédio 44, sala 5137, 97105-900 Santa Maria, RS, Brazil. E-mail: luana.vett@gmail.com, agueda.vargas@gmail.com. 

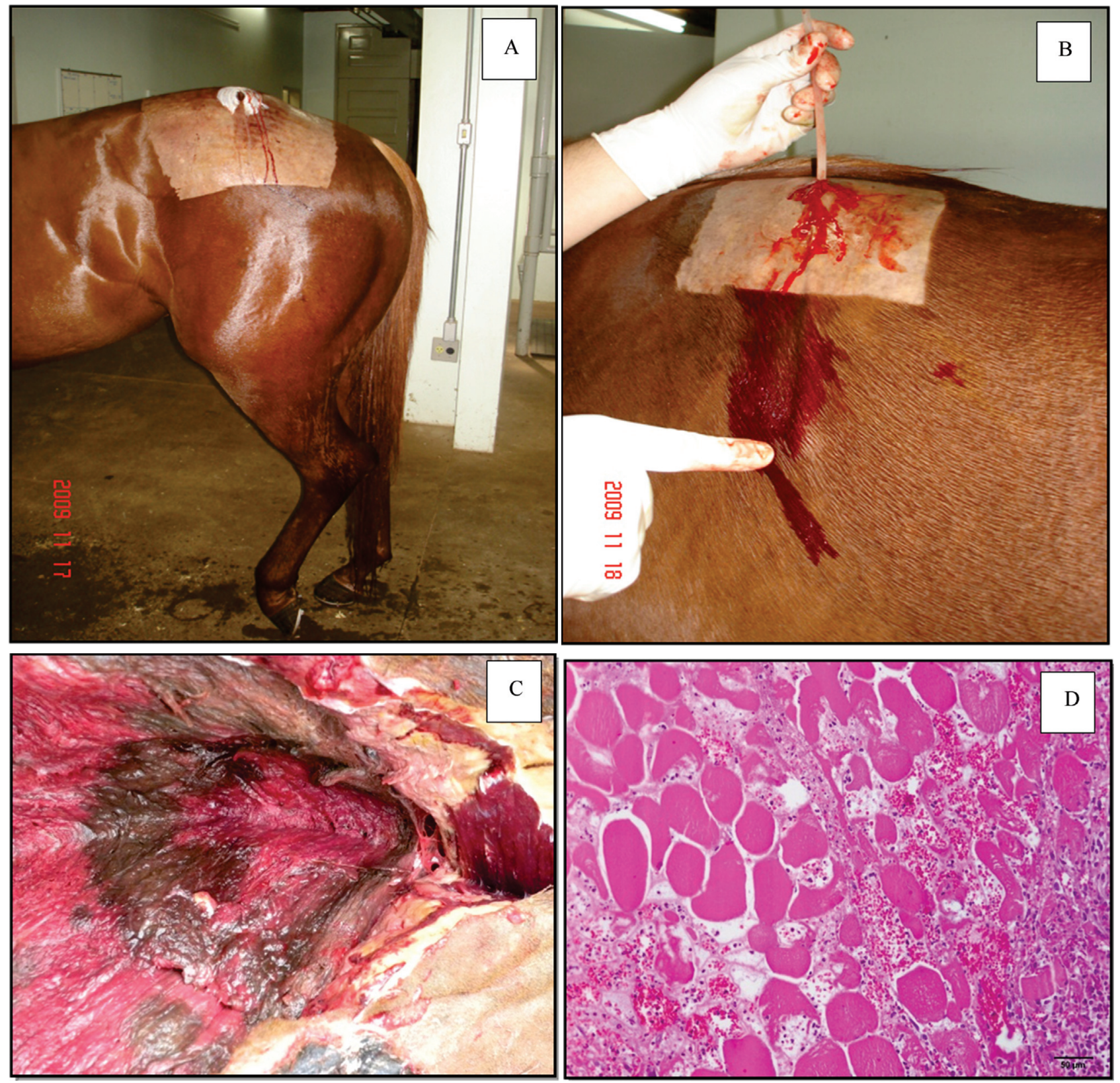

Figure 1 - (A) The increased in volume started in the gluteal muscle. (B) flexible pipette used for ablution in affected muscles. (C) Muscle necrosis observed at necropsy. (D) There are multifocal degeneration and necrosis of myofibers. Interstitial edema and hemorrhage and no inflammatory infiltrate with predominance of neutrophils. Hematoxylin-eosin. Obj. 10x.

the culture in reinforced clostridial medium showed pure large, gram-positive, spore-forming rods. In biochemical tests, the bacteria fermented glucose and maltose but not lactose, salicin, sorbitol or sucrose; these results were not sufficient for the accurate identification of the pathogen (Walker, 1990).

After six days of hospitalization, the prognosis of the horse was determined to be unfavorable, and the animal was euthanized. Necropsy was performed approximately 1 hour post-mortem. Tissue samples were collected and fixed in $10 \%$ buffered formalin, processed by routine histopatho- logy techniques, cut at a thickness of $5 \mu \mathrm{m}$ and stained with hematoxylin and eosin. At necropsy, the first description of the external examination with the location of the lesion (affected limb) was performed (Figure 1C). In some areas, subcutaneous crepitate swelling and a foul odor were present. Multifocal necrosis and the degeneration of myofibers were observed microscopically. In the interstitium, there was edema, hemorrhage and inflammatory infiltrate with a predominance of neutrophils (Figure D).

Definitive identification of the microorganism was performed by phylogenetic analysis based on a partial $16 \mathrm{~S}$ 
rDNA sequence. The sequencing reaction mixtures were sequenced in triplicate using an Genetic Analyser 3100 automatic DNA sequencer ABI PRISM ${ }^{\circledR}$ (Applied Biosystems, Foster City, CA). The SB258/09 consensus sequence of $680 \mathrm{bp}$ was identified using BLASTN (NCBI website). The phylogenetic analyses based on 16S rDNA sequences showed $97 \%$ similarity between the isolated microorganism (SB 258/09) and the 16S rDNA sequence of C. novyi type A deposited in GenBank (AB045606) (Figure 2).

The diagnosis of acute myonecrosis caused by Clostridium sp. in a horse was based on clinical signs, pathological findings and the visualization of the microorganism in the exudate from the injured muscle. The etiologic diagnosis of $C$. novyi type $\mathrm{A}$ was based on genetic analysis because the morphological and biochemical results were not sufficient. In other reports identification was also confirmed by parcial or full $16 \mathrm{~S}$ rDNA sequence analysis (McGuigan et al.; 2002; Aleman et al., 2003). The phylogenetic tree constructed to make the diagnosis presented here (Figure 2) agrees with the reported genetic relatedness among species of the genus Clostridium in other works (Collins et al., 1994; Sasaki et al., 2001).

C. novyi type A, previously called C. oedematiens, causes gas gangrene in humans and malignant edema in animals. In humans, C. novyi type A was recognized as a cause of septicemia among injecting drug users who use intramuscular injection (McGuigan et al., 2002). There have been only eight reported cases of infections of equines worldwide caused by $C$. novyi: five cases of acute necrotizing hepatitis, possibly caused by $C$. novyi type B or D (Dumaresq, 1939; Hollingsworth et al., 1978; Gay et al., 1980; Oaks et al., 1997); two cases of myonecrosis caused by a combination of $C$. novyi and $C$. septicum and by $C$. novyi alone, respectively (Graham, 1940; Valberg e McKinnon, 1984); and one case of a thoracic abscess from which $C$. novyi type A was isolated (Aleman et al., 2003). Therefore, this study is the first reported case of myonecrosis in a horse caused by $C$. novyi type A.

According to literature, most previously reported cases of clostridial myositis in horses developed after the intramuscular administration of nonantibiotic medication (Harwood, 1984; Brown, 1988; Peek et al., 2003; Raymundo et al., 2010). In these cases, the site of injection corresponded to site at which the clinical signs were first observed; therefore, it is assumed that the clostridial muscle infection resulted from the intramuscular injection. Although there is speculation about the manner in which clostridial spores are introduced into equine skeletal muscle and about the development of disease, some studies have raised the possibility of introducing spores via the medication or the needle (Breuhaus et al., 1983). Some researchers (Vengust et al., 2003), have shown that clostridial spores are dormant in healthy equine skeletal muscle. These researchers evaluated the hypothesis that dormant spores are capable of causing clostridial myonecrosis under the appropriate environmental conditions. Although other work (Brown, 1988) does not identify the injection site as an important factor for the development of the disease, it's suggest (Peek et al., 2003) that injection in the cervical region is a potential risk factor for clostridial myonecrosis. In this report, the application site was the gluteal muscle, an area more vascularized than the neck. However, the compound vitamin that was administered to the horse is considered to be a potential irritant, reinforcing the recommenda-

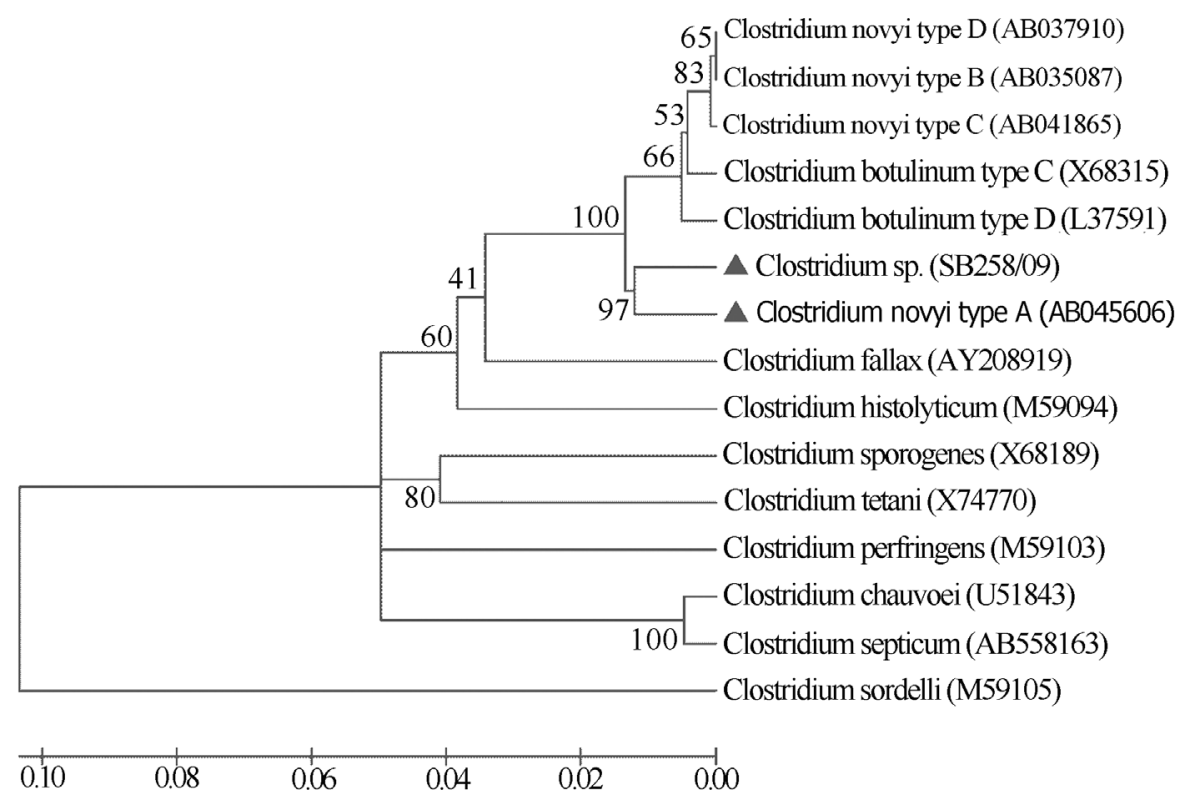

Figure 2 - The phylogenetic analyses based on 16S rDNA sequences by Neighbor-Joining (NJ) showing 97\% similarity between the 16S rRNA sequence of the microorganism (SB 258/09) and 16S rRNA sequence of C. novyi type A deposited in GenBank. 
tion of some authors to avoid the intramuscular injection of nonantibiotic medications into horses whenever possible (Breuhaus et al., 1983; Rebhun et al., 1985; Peek et al., 2003).

The treatment of the horse was performed according the reported protocols for other cases of malignant edema in horses (Rebhun et al., 1985; Peek et al., 2003 Valberg e McKinnon, 1984). However, the treatment was not successful, as in other studies of infections with $C$. novyi (Amimoto et al., 1998); the animal was euthanized on the sixth day of hospitalization.

The observed pathological lesions were similar to those found in reports of clostridial myositis in horses and included crepitant swelling and hemorrhage, as described previously (Valberg e McKinnon, 1984); muscle necrosis, as reported anteriorlyby (Peek et al., 2003; Valberg e McKinnon, 1984); and a malodorous exudate suggestive of anaerobic infection (Aleman et al., 2003). Histopathological evaluation revealed the presence of multifocal degeneration and necrosis of the myofibers, as also described previously (Valberg e McKinnon, 1984), as well as inflammatory infiltrate with a predominance of neutrophils.

This is the first report involving $C$. novyi type A as a causative agent of myonecrosis (malignant edema) in an equine, emphasizing the definitive diagnosis performed based on the phylogenetic analysis of the microorganism. Although there is a low incidence of C. novyi infection in horses, it is advisable to use alternative routes for the administration of nonantibiotic medications to avoid intramuscular injections, even in vascularized areas.

\section{Acknowledgments}

The authors thank to the Brazilian federal bureaus to facilitate scientific research (Conselho Nacional de Desenvolvimento Científico e Tecnológico/CNPq and Coordenação de Aperfeiçoamento de Pessoal de Nível Superior/CAPES) for the financial support and scholarship.

\section{References}

Aleman M, Watson JL, Jang SS (2003) Clostridium novyi Type A intra-abdominal abscess in a horse. $\mathrm{J}$ Vet Intern Med 17:934-936.

Amimoto K, Sasaki O, Isogai M, Kitajima T, Oishi E, Okada N, Yasuhara H (1998) The protective effect of Clostridium novyi type $\mathrm{B}$ alpha-toxoid against challenge with spores in guinea pigs. J Vet Med Sci 60:681-685.

Breuhaus BA, Brown CM, Scott EA, Ainsworth DM, Taylor RF (1983) Clostridial muscle infections following intramuscular injections in the horse. J Equine Vet Sci 3:42-46.

Brown CM, Kaneene JB, Walker RD (1988) Intramuscular injection techniques and the development of clostridial myositis or cellulitis in horses. JAVMA 193:668-670.
Choi YK, Kang MS, Yoo HS, Lee DY, Lee HC, Kim DY (2003) Clostridium perfringens type A myonecrosis in a horse in Korea. J Vet Med Sci 65:1245-1247.

Collins MD, Lawson PA, Willems A, Cordoba JJ, FernandezGarayzabal J, Garcia P, Cai J, Hippe H, Farrow JAE (1994) The phylogeny of the genus Clostridium: proposal of five new genera and eleven new species combinations. Int J Syst Bacteriol 44:812-816.

Coloe PJ, Ireland L, Vaudrey JC (1983) Clostridium fallax as a cause of gas-oedema disease in a horse. J Comp Path 93:597-601.

Dumaresq J (1939) A case of black disease in the horse. Aust Vet J 15:53-57.

Gay C, Lording P, McNeil P, Richards WPC (1980) Infectious necrotic hepatitis (black disease) in a horse. Equine Vet $\mathrm{J}$ 12:26-27.

Graham R (1940) Reactions in horses following inoculation of a chick-embryo vaccine. J Am Vet Assoc 97:38-39.

Hagemoser WA, Hoffman LJ, Lundval RL (1980) Clostridium chauvoei infeccion in horse. J Am Vet Med Assoc 176:631633.

Harwood DG (1984) Apparent iatrogenic clostridial myositis in cattle. Vet Rec 115:412.

Hollingsworth TC, Green VJD (1978) Focal necrotising hepatitis caused by Clostridium novyi in a horse. Aust Vet J 54:48.

McGuigan CC, Penrice GM, Gruer L, Ahmed S, Goldberg D, Black M, Salmon JE, Hood J (2002) Lethal outbreak of infection with Clostridium novyi type A and other sporeforming organisms in Scottish injecting drug users. J Med Microbiol 51:971-977.

Oaks JL, Kanaly ST, Fisher TJ, Besser TE (1997) Apparent Clostridium haemolyticum/Clostridium novyi infection and exotoxemia in two horses. J Vet Diagn Invest 9:324-325.

Peek SF, Semrad SD, Perkins GA (2003) Clostridial myonecrosis in horses (37 cases 1985-2000). Equine Vet J 35:86-92.

Raymundo DL, Pavarini SP, Bezerra PS, Antoniassi NAB, Bandarra PM, Bercht BS, Gomes MJP, Driemeier D (2010) Mionecrose aguda por Clostridium septicum em eqüinos. Pesq Vet Bras 30:637-640.

Rebhun WC, Shin SJ, King JM, Baum KH, Pattens V (1985) Malignant edema in horses. JAVMA 187:732-736.

Sasaki Y, Takikawa N, Kojima A, Norimatsu M, Suzuki S, Tamura Y (2001) Phylogenetic positios of Clostridium novyi and Clostridium haemolyticum based on 16S rDNA sequences. Int J Syst Evol Microbiol 51:901-904.

Songer JG (2010) Histotoxic clostridia. In: Gyles, C.L., Prescott, J.F., Songer, G., Thoen, C.O. (eds). Pathogenesis of Bacterial Infections in Animals. $4^{\text {th }}$ ed. Blackwell Publishing, Ames, pp. 203-209.

Valberg SJ, McKinnon AO (1984) Clostridial Cellulitis in the Horse: A Report of Five Cases. Can Vet J 25:67-71.

Vengust M, Arroyo LG, Weese JS, Baird JD (2003) Preliminary evidence for dormant clostridial spores in equine skeletal muscle. Equine Vet J 35:514-516.

Walker PD (1990) Clostridium. In: Carter, G.R., Cole, J.R. (eds.) Diagnostic Procedures in Veterinary Bacteriology and Mycology. $5^{\text {th }}$ ed. Academic Press, New York, pp. 229-251.

All the content of the journal, except where otherwise noted, is licensed under a Creative Commons License CC BY-NC. 